\title{
Hydrogen bonds and EDA bonds formed by ions
}

\author{
Pierre L. Huyskens \\ Department of Chemistry, University of Leuven, \\ Celestijnenlaan 200F, B-3030 Heverlee, Belgium
}

\begin{abstract}
Conductimetric and spectrometric techniques are major tools in the study of H-bonds and EDA-bonds involving ions. Several topics are reviewed : the effect of the various ion-ion and ion-neutral-ligand specific bonds on the association of ions; the influence of the dielectric permittivity of the medium on the stability of ion-ligand $\mathrm{H}$-bonds; the weakening of the other specific sites of an ion when a first one is involved in $\mathrm{H}-$ or EDA-bond formation; the strengthening of anion-ligand $\mathrm{H}$-bonds when the $\mathrm{A}-\mathrm{H}$ group of the ligand is connected with aromatic rings, due to charge induced electronic delocalization; the relation between the energy of $A-\ldots$. HB bonds in the gas phase and the difference of proton affinity between the ions $A^{-}$ and $\mathrm{B}^{-}$.
\end{abstract}

\section{INTRODUCTION}

Hydrogen bonds and n- $\sigma$ EDA bonds are short-range site-bonded cohesion forces that considerably weaken a given chemical bond of one of the partners (ref. 1). This weakening is evidenced by the decrease of the corresponding stretching frequency. In the case of $\mathrm{H}$-bonds, the chemical bond $\mathrm{A}-\mathrm{H}$ involves a hydrogen atom. Nitrogen bases, for instance, form $\mathrm{H}$-bonds with phenols and the O-H bond in the complexes is weakened; they also form EDA bonds with molecular iodine or bromine, and the I-I and $\mathrm{Br}-\mathrm{Br}$ stretching force constants are weakened. The similarity between these particular cohesion forces becomes evident when one considers the correlation between the energy of the specific bond and the decrease of the stretching frequency $v(\mathrm{ap})$ of the perturbed chemical bond. As can be seen from Fig. 1, for a given type of electron donor in a given solvent, the correlation between the molar enthalpy $-\Delta \mathrm{H}$ of $\mathrm{H}$-bonds and $n-\sigma$ EDA bonds and $\Delta \ln \nu(\mathrm{ap})$ of the chemical bond is, to a first approximation, the same for both types of specific bonds.

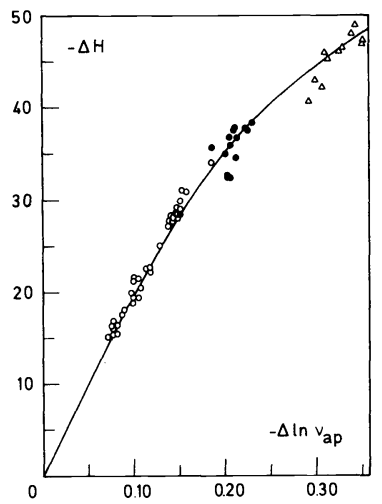

Fig. 1. Molar enthalpy of formation $-\Delta \mathrm{H} / \mathrm{kJ} \mathrm{mol}^{-1}$ of H-bonds and EDA-bonds compared with the decrease of the logarithm of the stretching frequency $v(\mathrm{ap})$ of the weakened chemical bond. Electron donors : pyridines and triethylamine. (o) : N...HO bonds with alcohols and phenols;

(๑) : N...I-I bonds (ref. 1).

( $\Delta)$ : N...Br-Br bonds (ref. 2).

Thus, H-bonds and n- $\sigma$ EDA bonds are concurrents of chemical bonds. They share already two of their most fundamental features : the directional character and the stoichiometry. The dipole moments in the liquid phase show indeed that the direction of an $\mathrm{H}$-bond with respect to the proton acceptor is fixed within narrow limits at the opposite of pure dipole-dipole interactions (ref. 3). From this point of view an hydrogen bond resembles more a covalent chemical bond. On the other hand, the number of $\mathrm{H}$-bonds or $n-\sigma$ EDA bonds a given molecule can form with its neighbours is limited by the number of electron-donor or electron-acceptor sites in this molecule. A direct consequence of this stoichiometric character is that, in contrast to pure dipole-dipole interactions (even very strong), the H-bonds or $n-\sigma$ EDA bonds a given molecule or ion can form in the liquid state or in solution, are characterized by distinct stability constants $\mathrm{K}_{1}, \mathrm{~K}_{2} \ldots$ and corresponding enthalpy changes $\Delta \mathrm{H}_{1}, \Delta \mathrm{H}_{2} \ldots$ 


\section{INFLUENCE OF HYDROGEN BONDS AND EDA BONDS ON ASSOCIATION OF IONS}

Hydrogen bonds can also be formed by ions. The existence of cation-anion H-bonds was postulated as early as 1931 by Wynne-Jones (ref. 4) in order to explain the differences between the association constants $\mathrm{K}_{\mathrm{O}}^{\circ}$ of alkylammonium salts in nitrobenzene. The tetraalkylammonium salts are indeed much more dissociated than the tri-, di- or monoalkylammonium salts. The latter can form with the picrate ion H-bonds of the form<smiles></smiles>

A rough quantitative evaluation of the effect of the cation-anion $\mathrm{H}$-bond on the association constant $\mathrm{K}_{\AA}^{\circ}$ can be made by comparing its experimental value with that ( $\mathrm{K}_{\AA}^{\circ \circ}$ ) predicted from the expressions of Fuoss (ref. 5) and Denison and Ramsey (ref.6) for the same ionophore in the absence of specific interactions:

$$
\mathrm{K}_{\AA}^{\circ \circ}=\frac{4}{3} \pi \mathrm{N} \mathrm{a}^{3} \times 10^{\mathrm{m}}\left(\exp \frac{\mathrm{e}_{\mathrm{O}}^{2} \mathrm{~N}}{4 \pi \varepsilon_{\mathrm{O}} \varepsilon a k \mathrm{kT}}\right)
$$

In the pre-exponential term of Fuoss, $a$ is the distance of closest approach between the chargeş, $m_{-1}$ conversion factor depending of the choice of the units (when $\mathrm{K}_{\mathrm{A}}^{\circ}$ is expressed in $\mathrm{dm}^{\mathrm{mol}}{ }^{-1}+3$ if SI units are used, -3 with cgs units (ref. 7). In the exponential factor of Denison and Ramsey, $e_{o}$ is the elementary charge, $N$ the Avogadro number, $\varepsilon_{a}$ the permittivity of vacuum, $\varepsilon$ the relative dielectric constant, $k$ the Boltzmann constant, and $\mathrm{T}$ the absolute temperature. The distance a can be calculated to a first approximation from the dependence of the experimental association constant on the dielectric constant of the medium, using the equation of Denison and Rarisey

$$
\mathrm{a}=\frac{\mathrm{e}_{\mathrm{O}}}{4 \pi \varepsilon_{\mathrm{O}} \mathrm{kT}} \quad\left[\mathrm{d} \ln \mathrm{k}_{\mathrm{A}} / \mathrm{d}(1 / \varepsilon)\right]
$$

The results for the butylammonium picrates are listed in Table 1.

TABLE 1. Effect of $\mathrm{NH}^{+} . . \mathrm{O}^{-}$hydrogen bonds on the association constants of butylammonium picrates in nitrobenzene at $25^{\circ} \mathrm{C}$

\begin{tabular}{lllllccc}
\hline Ionophore & $\mathrm{a} / \mathrm{nm}$ & ref. & $\mathrm{K}_{\mathrm{A}}^{\circ} / \mathrm{dm}^{3} \mathrm{~mol}$ & ref. & $\mathrm{K}_{\mathrm{A}}^{\circ} \% \mathrm{dm}^{3} \mathrm{~mol}^{-1}$ & $\mathrm{~K}_{\mathrm{A}}^{\circ} / \mathrm{K}_{\mathrm{A}}^{\circ \circ}$ & $-\Delta \mathrm{G}_{\mathrm{h}}^{*} / \mathrm{kJmol}^{-1}$ \\
\hline $\mathrm{Bu}_{4} \mathrm{~N}^{+} \mathrm{Pi}^{-}$ & 0.591 & $(8)$ & 7.5 & $(8)$ & 7.9 & 0.95 & - \\
$\mathrm{Bu}_{3} \mathrm{NH}^{+} \mathrm{Pi}^{-}$ & 0.588 & $(9)$ & 5260 & $(10)$ & 7.9 & 666 & 16.12 \\
$\mathrm{Bu}_{2} \mathrm{NH}_{2}^{+} \mathrm{Pi}^{-}$ & 0.510 & $(9)$ & 6410 & $(10)$ & 7.8 & 821 & 16.64 \\
$\mathrm{BuNH}_{3}^{+} \mathrm{Pi}^{-}$ & 0.451 & $(11)$ & 6620 & $(10)$ & 8.2 & 807 & 16.54 \\
\hline
\end{tabular}

Equation 1 implies that all ions at a distance from the counter-ions larger than a contribute to the conductivity. According to Bjerrum (ref. 12) this is only the case above a certain critical distance q given by

$$
\mathrm{q}=\mathrm{e}_{\mathrm{o}}^{2} /\left(8 \pi \varepsilon_{\mathrm{o}} \varepsilon \mathrm{kT}\right)
$$

The more refined theory of Barthel (ref. 7) divides the space around the central ions in several regions. Above a distance $R$, the approach of Debye and Hückel can be used. In the assumption of Bjerrum $R=q$, but other $R$ values are also possible. Barthel considers the short-range forces in the region between $a$ and $R$, with a limiting interdistance $R^{*}$, and his equation can be written

$$
\mathrm{K}_{\mathrm{A}}^{\circ}=4 \pi \mathrm{N} \cdot 10^{\mathrm{m}}\left[\left(\exp \frac{-\Delta \mathrm{G}_{\mathrm{A}}^{\star}}{\mathrm{RT}}\right) \int_{\mathrm{a}}^{\mathrm{R}^{*}} \mathrm{r}^{2} \exp \frac{2 \mathrm{q}}{r} \mathrm{dr}+\int_{\mathrm{R}^{*}}^{\mathrm{R}} \mathrm{r}^{2} \exp \frac{2 \mathrm{q}}{r} \mathrm{dr}\right]
$$

$\Delta G^{*}$ is that part of the molar Gibbs energy of ion-pair formation which is due to the shortrange interactions. An hydrogen bond between the anion and the cation increases considerably the value of $\left(-\Delta G_{A}^{*}\right)$ and of the association constant. To a first approximation $\left(-\Delta G_{h}^{*}\right)$ for the systems of Table 1 corresponds to RT ln $\mathrm{K}_{\mathrm{A}}^{\circ} / \mathrm{K}_{\mathrm{A}}^{\circ \circ}$.

But hydrogen bonds and EDA bonds can also be formed between ions and neutral ligands or solvent molecules. In such specific ion-molecule bonds the cations act in general as proton donors or electron acceptors and the anions as proton acceptor or electron donors. For instance trialkylammonium ions form H-bonds with pyridine and iodide ions act as proton acceptor for phenol molecules : 


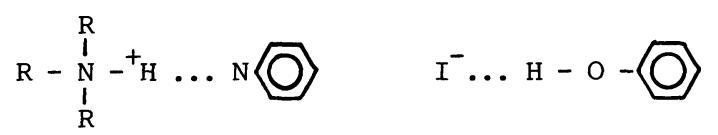

Such interactions were called "heteroconjugation" of the ions by Kolthoff and Chantooni (ref. 13). "Homoconjugation" occurs when the ligand is the neutral precursor of the ion :

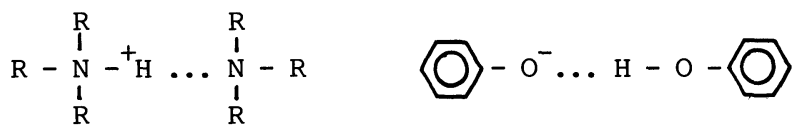

Homoconjugation by EDA bonds exists for instance in

$$
\text { (O) } N{ }^{+} I \ldots N \quad \text { or } \quad I^{-} \ldots I-I
$$

Many ions possess more than one specific site and the interaction with neutral ligands leads to the formation of complexes of higher stoichiometry. For instance

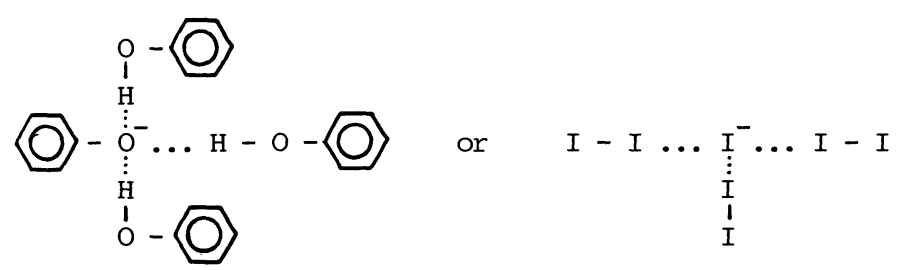

The formation of bulky polysolvated ions has unexpected effects on the viscosity of the systems. We found for instance that, due to their presence in mixtures of $4-\mathrm{NO}_{2}$ phenol and triethylamine, the viscosity reaches $8000 \mathrm{cp}$ in the vicinity of a mole fraction ${ }^{2} .75$ of phenol at $25^{\circ} \mathrm{C}$ (ref. 14).

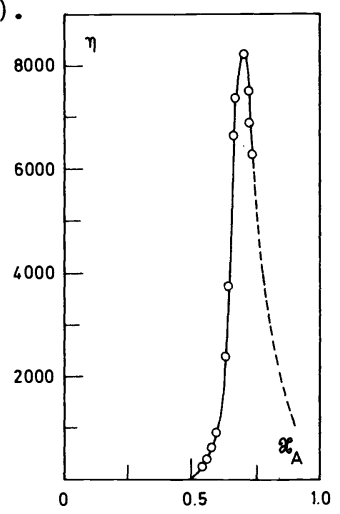

Fig. 2. Effect of trisolvated $4-\mathrm{NO}_{2}$ phenolate anions on the viscosity $n /$ cpoise of binary $4-\mathrm{NO}_{2}$ phenoltriethylamine mixtures at $25^{\circ} \mathrm{C}$ (ref. 14)

Hydrogen bonds or EDA bonds between free conducting ions and neutral molecules yield a negative contribution to the short-range free energy term $\left(-\Delta G_{A}^{*}\right)$ of the equation of Barthel and thus disfavour the association of cations and anions.

On the other hand it may happen that ions already bound with the counter-ion possess still active sites for H-bond (or EDA-bond) formation with ligands. Hydrogen bonds between ligands and ion pairs as for instance

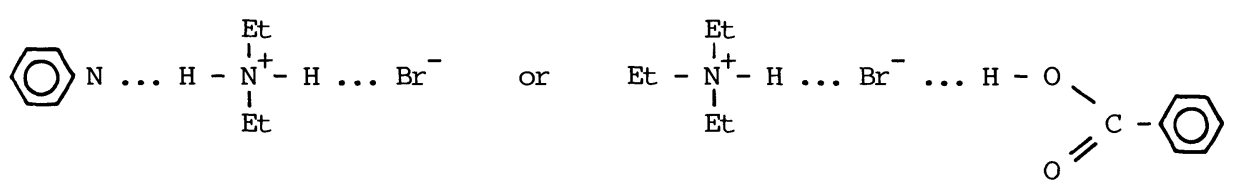

give a positive contribution to $\left(-\Delta \mathrm{G}_{\mathrm{A}}^{*}\right)$ and favour ionic association.

A particular case that can be expected with amphiprotic ligands is that of the formation of "solvent" or "ligand" separated ion-pairs, for instance

$$
\mathrm{Et}-\stackrel{\mathrm{N}}{\mathrm{N}}_{\mathrm{Et}}^{\mathrm{Et}}-{ }^{+} \mathrm{H} \ldots \mathrm{O}_{\mathrm{O}}^{\mathrm{O}}-\mathrm{H} \ldots \mathrm{Br}^{-}
$$


The concept of solvent separated ion pairs was introduced by Winstein (ref. 15) and developed by Szwarc (ref. 16).

When a ligand is present in the solution, its effect on the $\left(-\Delta G_{A}^{*}\right)$ value of Barthel's equation will depend on its concentration. If the dielectric constant $\varepsilon$ (and thus the $q$ factor) remains unchanged, this effect can be described by the following equation :

$$
\begin{aligned}
& \left(\Delta G_{A}^{*}\right)_{L}-\left(\Delta G_{A}^{*}\right)_{O}=R T\left[\ln \left(1+k_{1}^{+} L_{1}+k_{1}^{+} k_{2}^{+}{ }^{2} \ldots\right)+\ln \left(1+k_{1}^{-}+k_{1}^{-}-k_{2}^{-}{ }^{2} \ldots\right)\right. \\
& \left.-\ln \left(1+K_{1} L+K_{1} K_{2} L^{2} \ldots\right)\right]
\end{aligned}
$$

where $\mathrm{L}$ is the concentration of free ligand, $\mathrm{k}_{1}^{+}, \mathrm{k}_{2}^{+}$the equilibrium constants for the addition of a first or a second ligand molecule on the free cations, $\mathrm{k}_{1}^{-}, \mathrm{k}_{2}^{-}$the addition constants on the free anions and $\mathrm{K}_{1}, \mathrm{~K}_{2}$ the addition constants on the still available sites of
the ion-pairs.

If $\mathrm{K}_{\mathrm{A}}$ and $\mathrm{K}_{\mathrm{A}}^{\circ}$ are the association constants of the ions, respectively, in presence of the ligand at the concentration $\mathrm{L}$ and in absence of it, the previous equations lead to the following expression (ref. 9)

$$
\frac{\mathrm{K}_{\mathrm{A}}^{\circ}}{\mathrm{K}_{\mathrm{A}}} \equiv \mathrm{R}=\frac{\left(1+\mathrm{k}_{1}^{+} \mathrm{L}+\mathrm{k}_{1}^{+} \mathrm{k}_{2}^{+} \mathrm{L}^{2} \ldots\right)\left(1+\mathrm{k}_{1}^{-} \mathrm{L}+\mathrm{k}_{1}^{-} \mathrm{k}_{2}^{-}{ }^{2} \ldots\right)}{1+\mathrm{K}_{1} \mathrm{~L}+\mathrm{K}_{1} \mathrm{~K}_{2} \mathrm{~L}^{2} \ldots}
$$

In 1971 we presented this equation as a generalization of that of Gilkerson (reff. 17). In principle it allows the determination of the various stability constants $k_{1}^{+}, k_{2}^{+} \cdots$ from the
dependence of the ratio $\mathrm{R}$ on the ligand concentration $\mathrm{L}$.

However, a ligand added to the solution can modify the dielectric permittivity and this influences the Bjerrum distance $q$, appearing in Barthel's equation. It may be, therefore, useful to correct $\mathrm{K}_{\mathrm{A}}$ for the changes of the dielectric constant. For this purpose eq. 2 can be used to a good approximation. The value of the parameter a can be obtained by measuring $K_{\AA}^{\circ}$ in absence of ligands in mixed solvents, as for instance nitrobenzene-benzene.

For a given solution, the association constant $\mathrm{K}_{\mathrm{A}}$ can be calculated from the formal concentration of the ionophore $F$, the concentration of conducting ions [i] and their activity coefficient $y_{+} \cdot$ For single charged ions the expression is

$$
\mathrm{K}_{\mathrm{A}}=\frac{(\mathrm{F}-[\mathrm{i}])}{[i]^{2} \mathrm{Y}_{ \pm}^{2} \mathrm{~F}^{2}}
$$

The activity coefficients are calculated by the classical equation of Debye and Hückel, from the parameter $k$ and from the distance $R$ considered in Equation 4

$$
y_{ \pm}=\exp [-\kappa q /(1+\kappa R)]
$$

$\kappa$ is given by (ref. 7)

$$
\kappa^{2}=16 \pi q N[i] \cdot 10^{m}
$$

The concentration of the conducting ions [i] can be calculated from the specific conductance 1 and from the viscosity of the system, by the following equation which holds for single charged ions :

$$
[i]=10^{m}\left(1-1^{\circ}\right) \mathrm{n} / \mathrm{W}
$$

$1^{\circ}$ is the conductance in absence of the ionophore, $\eta$ the viscosity and $W$ the overall Walden product, corresponding to the sum of those of the cations and the anions :

$$
\mathrm{w}=\mathrm{w}^{+}+\mathrm{w}^{-}
$$

The Walden product decreases with increasing concentration [i] of the conducting ions. At low ionic concentrations, one can use the limiting Onsager relation (ref. 18). In cgs units, this relation can be written

$$
\mathrm{W}=\mathrm{W}^{\circ}-\left\{\frac{8.204 \times 10^{3} \mathrm{~W}^{\circ}}{(\varepsilon \mathrm{T})^{3 / 2}}+\frac{0.8250}{(\varepsilon \mathrm{T})^{1 / 2}}\right\}[\mathrm{i}]^{1 / 2}
$$

The limiting Walden product $\mathrm{W}^{\circ}$ can be found by extrapolation of the conductance data at zero ionic concentration, or from the individual walden products of the ions determined in other systems. Fuoss (ref. 19) has developed a method allowing to compute both $\mathrm{W}^{\circ}$ and $\mathrm{K}_{\mathrm{A}}$ values from conductance measurements at increasing concentrations $\mathrm{F}$ of the ionophore. 
The limiting value of the Walden product $\mathrm{w}^{\circ}$ decreases upon addition of a ligand to the solution. The individual Walden products of the ions must indeed decrease when they are solvated by one or more ligand molecules. We have presented a more quantitative treatment of this effect in the case of anions solvated by citric acid or benzoic acids (ref. 20).

From the measurements of the electric conductance, the viscosity of the solutions (and their dielectric constant in absence of ionophores $d$ it is possible to determine the value of the ratio $\mathrm{R} \equiv \mathrm{K} \circ / \mathrm{K}_{\mathrm{A}}$. When plotting $\mathrm{R}$ against the concentration $\mathrm{L}$ of the ligand, three cases are found in the practice :

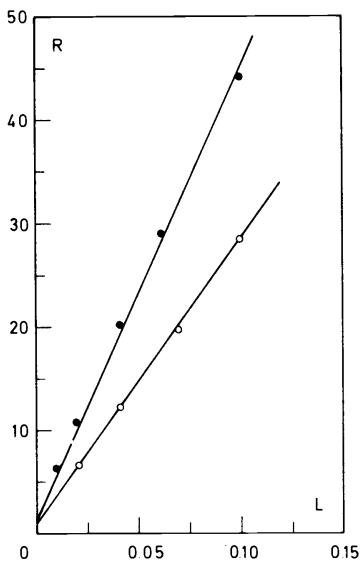

Fig. 3. Ratio's $\mathrm{R}=\mathrm{K} \circ / \mathrm{K}_{\mathrm{A}}$ for $\mathrm{Et}_{3} \mathrm{NH}^{+} \mathrm{PiC}{ }^{-}$ as a function of the concentration $\mathrm{L} /$ moledm $^{-3}$ of added imidazole : (o) in nitrobenzene; (•) in a $60 / 40$ volume percent mixture of nitrobenzene and benzene (at $25^{\circ} \mathrm{C}$ ) (ref. ll)

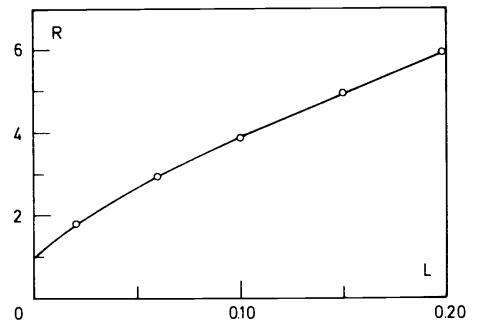

Fig. 4. Ratio $\mathrm{R}=\mathrm{K}_{\mathrm{A}} / \mathrm{K}_{\mathrm{A}}$ for $\mathrm{Et}_{2} \mathrm{NH}^{+} \mathrm{Pic}{ }^{-}$ in nitrobenzene ${ }^{\mathrm{A}}$ at $25^{\circ} \mathrm{C}$ as a function of the concentration $\mathrm{L} / \mathrm{mol} \mathrm{\textrm {dm } ^ { - 3 }}$ of added 3,4-lutidine (ref. 22).

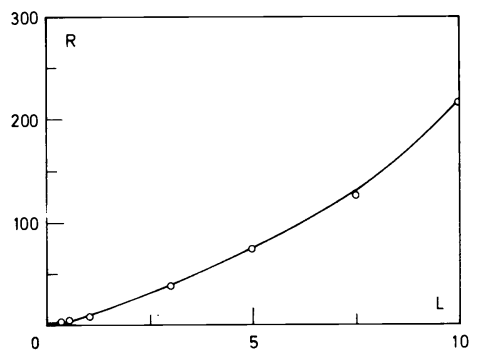

Fig. 5. Ratio $\mathrm{R}=\mathrm{K}_{\mathrm{A}}^{\circ} / \mathrm{K}_{\mathrm{A}}$ for $\mathrm{Bu}_{3} \mathrm{NH}^{+} \mathrm{PiC}{ }^{-}$ in nitrobenzene at $25^{\circ} \mathrm{C}$ as a function of the concentration $\mathrm{L} / \mathrm{mol} \mathrm{dm}^{-3}$ of added methanol (ref. 9).
1. The function gives a straight line passing through one at the origin. This behaviour indicates that only one of the ions (either the cations or the anion) is solvated by only one molecule of the ligand, the ion pair remaining unsolvated. In such cases eq. 6 reduces indeed to

$$
\mathrm{R}=1+\mathrm{k}_{1}^{+} \mathrm{L} \quad \text { or } \quad 1+\mathrm{k}_{1}^{-} \mathrm{L}
$$

The value of the stability constant is then given by the slope of the line. Numerous examples can be found in the literature (Gilkerson, ref. 17; Coetzee, ref. 21; and others). We show in Fig. 3 the effect of methylimidazole on the association constant of methylimidazolium picrate studied by Van Even and Haulait-Pirson (ref. 1l). The slope is here due to the formation of a cation-ligand hydrogen bond<smiles></smiles>

2. The function exhibits a downward curvature. This demonstrates unambiguously the solvation of the ion pairs by the ligand. It is observed, for instance, when 3,4-lutidine is added to a nitrobenzene solution of $\mathrm{Et}_{2} \mathrm{NH}_{2}^{+} \mathrm{Pic}$ (Fig. 4) (ref. 22). The experimental points fit the equation

$$
R=\frac{1+61 L+(61)(5) L^{2}}{1+11 L}
$$

The downward curvature is due to the fact that the addition constant $\mathrm{K}_{1}$ of 3,4-lutidine on the second $\mathrm{N}-\mathrm{H}$ site of the ion-pair is stronger than the addition constant $\mathrm{k}_{2}^{+}$of this ligand on the second $\mathrm{N}-\mathrm{H}$ site of the free cation.

3. The graph $R$ versus $L$ has an upward curvature. This is observed for instance with amphiprotic ligands as alcohols or unsubstituted imidazole. Sometimes, $\mathrm{R}$ follows the equation

$$
R=\left(1+k_{1}^{+} L\right)\left(1+k_{1}^{-} L\right)
$$

as for instance in the case of methanol interacting with tributylammonium picrate in nitrobenzene (ref. 9) (Fig. 5) where the constants are of the order of 5 and $0.4 \mathrm{dm}^{-1}$. Other systems with positive curvature follow an equation of the same form as eq. 14 :

$$
\mathrm{R}=\left(1+\mathrm{k}_{1} \overline{\mathrm{L}}+\mathrm{k}_{1} \overline{\mathrm{k}_{2}} \overline{\mathrm{L}}^{2}\right) /\left(1+\mathrm{K}_{1} \mathrm{~L}\right)
$$

where however $\mathrm{K}_{1}<\mathrm{k}_{2}$. An example is that of $4-\mathrm{NO}_{2}$ phenol interacting with halogenides (ref. 23). 


\section{INFLUENCE OF DIELECTRIC PERMITTIVITY ON STABILITY OF ION- MOLECULE H-BONDS}

The dielectric constant of a medium can be changed by mixing a solvent of low polarity with a more polar one, for instance benzene with nitrobenzene. When studying the effect of the dielectric permittivity one should take care, as emphasized by Sobczyk (ref. 24), that changes in specific effects would not overshadow that of the dielectric constant.

As a general rule it can be said that an increase of the dielectric constant disfavours the stability of the specific bonds between an ion and a neutral molecule.

This general effect can be explained in the following way : an increase of the dielectric constant corresponds to an increase of the concentration of electric dipoles of the medium (or an increase of their dipole moments). These electric dipoles orientate themselves around the charged particles and this phenomenon leads to the stabilization of the latter. The stabilization depends on the distance between the charges and the surrounding dipoles. In complexed ions, the presence of the ligand increases the distance between the charge of the ion and the dipoles of the solvent. As a consequence an increase of the dielectric constant favours more the non complexed than the complexed ions. As a matter of fact the stability constants $\mathrm{k}_{1}^{+}$ of the homoconjugated methylimidazole-methylimidazolium ions determined by Van Even and Haulait-Pirson (ref. 1l) decrease when the dielectric permittivity rises. These authors have found the following relation (Fig. 6) :

$$
\ln \mathrm{k}_{1}^{+}=4.96+23.2 / \varepsilon \quad(r=0.999)
$$

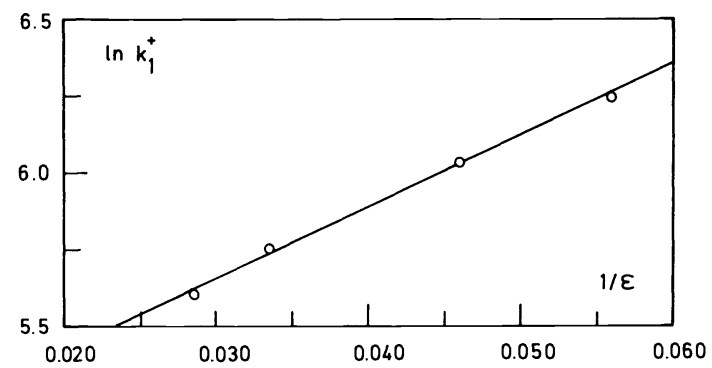

Fi.g. 6. In $\mathrm{k}^{+}$of the addition constant of methylimidazole on the methylimidazolium ion in nitrobenzene-benzene mixtures as a function of the inverse of the dielectric constant at $25^{\circ} \mathrm{C}$.

The more quantitative treatment of Haulait-Pirson considers both complexed and non complexed ions as spheres with radii $r_{i}$ and $r_{j}$. These radii are calculated to a rough approximation from the molar volumes $\bar{V}_{i}$ and $\bar{V}_{L}$ of ${ }^{i}$ the ion and of the ligand according to the expressions

$$
r_{i}=\left(3 \bar{v}_{i} / 4 \pi N\right)^{1 / 3} \quad \text { and } \quad r_{i L}=\left(3\left(\bar{V}_{i}+\bar{V}_{L}\right) / 4 \pi N\right)^{1 / 3}
$$

From the Born's equation (ref. 25), the following expression is deduced :

$$
\mathrm{dlnk}_{1}^{+} / \mathrm{d}(1 / \varepsilon)=\frac{\mathrm{e}_{\mathrm{O}}^{2}}{4 \pi \varepsilon_{\mathrm{O}} \mathrm{kT}}\left(1 / 2 r_{i}-1 / 2 r_{i L}\right)
$$

Taking molar volumes $\bar{V}_{i}\left(\mathrm{MeImH}^{+}\right)$and $\overline{\mathrm{V}}_{\mathrm{L}}$ (MeIm) both of $80 \mathrm{~cm}^{3} \mathrm{~mol}{ }^{-1}$, a slope $\left(\mathrm{dlnk}_{1}^{+} / \mathrm{de}^{-1}\right.$ ) of 18.2 can be calculated. Owing to the $L_{\text {fact }}$ that the solvated ion strongly deviates from the sphericity the agreement with the experimental value of 23.2 can be considered as satisfactory.

\section{INFLUENCE OF A FIRST SPECIFIC BOND FORMED BY AN ION ON STRENGTH OF OTHER SPECIFIC SITES}

A qualitative answer to this question can be found in the theories of Frank and Wen (ref. 26) and of Gutmann (ref. 27). A first specific bond involving a given site of an ion weakens the reactivity of the neighbouring sites of the same nature, whereas it enhances the electron donor or electron acceptor power of the adjacent sites of opposite nature. As a consequence one expects that the second addition constant will be always smaller than the first one : $\mathrm{k}_{2}^{+}<\mathrm{k}_{1}^{+} ; \mathrm{k}_{2}^{-}<\mathrm{k}_{1}^{-} ; \mathrm{K}_{2}<\mathrm{K}_{1}$. Furthermore when a given site of an ion in an ion-pair is involved in a specific bond with the counter ion and when $\mathrm{K}_{1}$ concerns a second site of the same nature, $\mathrm{K}_{1}<\mathrm{k}_{1}$ or $\mathrm{k}_{1}^{-}$.

The homoconjugation constants of the iodide ion leading to the formation $\mathrm{I}_{3}^{-}, \mathrm{I}_{5}^{-}, \mathrm{I}_{7}^{-}$decrease indeed in this order : in nitrobenzene at $25^{\circ} \mathrm{C} \mathrm{k}_{1}$ is of the order of
$10^{6} \mathrm{dm} \mathrm{mol}$

From a quantitative point of view the fundamental question is : which characteristic of the first specific bond is the driving factor for the weakening of the other specific sites ? A priori, this characteristic may be the strength of the first bond, quantitatively described either by the molar change in enthalpy $-\Delta \mathrm{H}_{1}^{\Theta}$ or in standard free energy $-\Delta G_{1}^{\ominus}$. But the leading factor may also be the amount of electronic charge transferred from one partner to the other 
in the first specific bond. This electron transfer is directly related to the weakening of the chemical bond and therefore to the decrease of the corresponding stretching frequency $-\Delta \nu_{1}$. However, in a given family of complexes, the $\Delta \mathrm{H}_{1}, \Delta \mathrm{G}_{1}^{\Theta}$ and $\Delta \nu_{1}$ values are generally correlated. As a consequence, when there exists a correlation between the weakening $\mathrm{K}_{2} / \mathrm{K}_{1}$ and $-\Delta G_{1}^{\ominus}$, a correlation between $\mathrm{K}_{2} / \mathrm{K}_{1}$ and $-\Delta v_{1}$ is also expected.

This is the case, for instance for the halogenide ions of the ion pairs $\mathrm{Br}^{-}\left(\mathrm{Bu}_{4} \mathrm{~N}^{+}\right)$and $\mathrm{I}^{-}\left(\right.$Hept $\mathrm{N}^{+}$) in benzene solution, studied by Rulinda and Zeegers-Huyskens (ref. ${ }^{29}$ ). These authors determined the addition constants $\mathrm{K}_{2}$ and $\mathrm{K}_{1}$ of substituted phenols of increasing strength. From their data one deduces the correlations (Fig. 7 and Fig. 8) :

and

$$
\text { In } \mathrm{K}_{2} / \mathrm{K}_{1}=0.36-0.1492\left(-\Delta \mathrm{G}_{1}^{\ominus}\right) \cdot / \mathrm{kJ} \mathrm{mol}^{-1}
$$

ln $\mathrm{K}_{2} / \mathrm{K}_{1}=1.60-0.00856\left(-\Delta \tilde{v}_{1}\right) / \mathrm{cm}^{-1}$

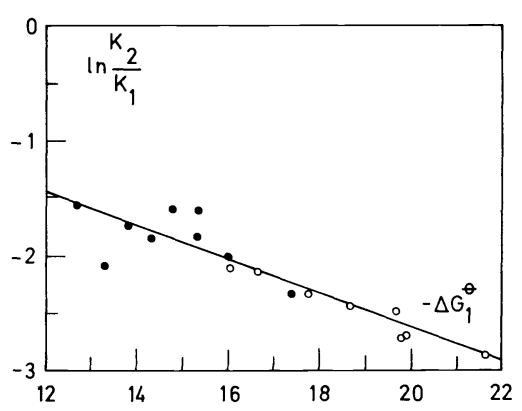

Fig. 7. Ln $\mathrm{K}_{2} / \mathrm{K}_{1}$ of the addition constants of substituted phenols on the halide ions in the ion pairs Hept $\mathrm{N}^{+} \mathrm{I}^{-}$ (•) and $\mathrm{Bu}_{4} \mathrm{~N}^{+} \mathrm{Br}^{-}$(o) in $\mathrm{CCl}_{4}$ as a function of the standard free energy of formation of the first $\mathrm{H}$-bond $\Delta G_{1}^{\ominus} / \mathrm{kJmole}^{-1}$ (ref. 29).

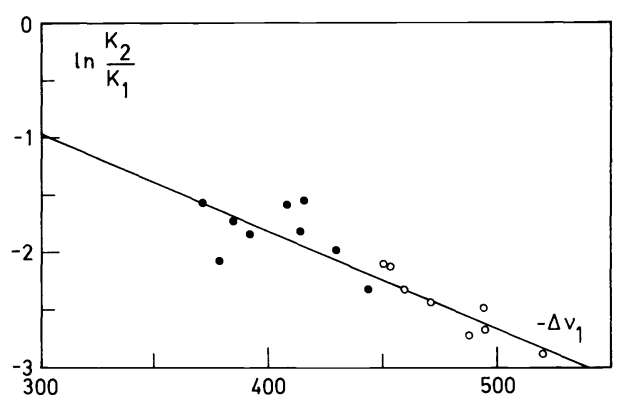

Fig. 8. Ln $\mathrm{K}_{2} / \mathrm{K}_{1}$ of the addition constants of substituted phenols on the halide ions in Hept $\mathrm{N}^{+} \mathrm{I}^{-}(\bullet)$ and $\mathrm{Bu}_{4} \mathrm{~N}^{+} \mathrm{Br}{ }^{-}$(O) in $\mathrm{CCl}_{4}^{4}$ as a function of the shift $\Delta v_{1} / \mathrm{cm}^{-1}$ brought about in the $\mathrm{O}-\mathrm{H}$ frequency by the first $\mathrm{H}$-bond (ref. 29).

In a similar way one can study the influence of a cation-anion hydrogen bond on the strength of the other specific sites by comparing the ratio $K_{1} / k_{1}^{+}$and the characteristics $\Delta G_{A}^{\theta}$ and $\Delta \nu_{A}$ of the cation-anion bond. We have determined the reduction ratio $\mathrm{K}_{1} / \mathrm{k}_{1}^{+}$for the complexation of the diethylammonium ion by 3,4-lutidine in nitrobenzene, the counter ions being $\mathrm{ClO}_{4}^{-}, \mathrm{Br}^{-}$ and $\mathrm{Cl}^{-}$, respectively (ref. 30 and ref. 31). The experimental results yielded the following expressions :

and

$$
\begin{aligned}
& \ln \mathrm{K} / \mathrm{k}_{1}^{+}=0.092-0.0659\left(-\Delta G_{\mathrm{A}}^{\ominus}\right) / \mathrm{kJ} \mathrm{mol}^{-1} \\
& \ln \mathrm{K} / \mathrm{k}_{1}^{+}=-0.42-0.00249\left(-\Delta \tilde{v}_{\mathrm{A}}\right) / \mathrm{cm}^{-1}
\end{aligned}
$$

We will try now to extend these calculations for predicting the value of $\ln \mathrm{k}_{2}^{+} / \mathrm{k}^{+}$corresponding to the addition of a second lutidine molecule on the monosolvated cation from $-\Delta G^{\Theta}$ and $-\Delta v$, using the same coefficients. Equation 21 yields a value of -0.58 and eq. 22 a value of -2.66 , very near to the experimental value of -2.48 . Equation 22 can thus still be applied when the first bond is an ion-ligand bond instead of a cation-anion hydrogen bond. This conclusion is confirmed by other experimental points as can be seen from Fig. 9.

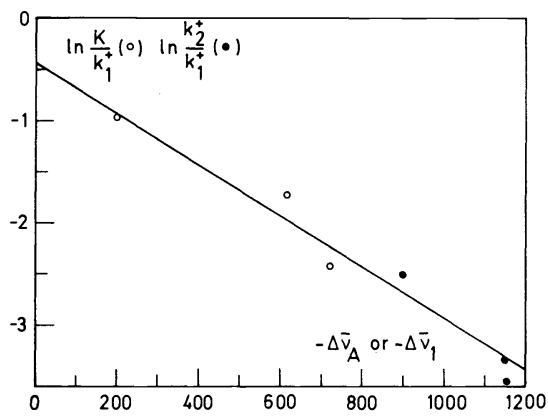

Fig. 9. Weakening of the second site $\mathrm{N}-\mathrm{H}$ of a dialkyl- or monoalkylammonium ion involved in a first $\mathrm{H}$-bond : (o) with a counter-ion; ( $\bullet$ with a first molecule of the same ligand. (Points from ref. 31). 
The correlations between the reduction ratio and the $\Delta v$ value for the first bond seem thus to be more general than those between the reduction ratio and $\Delta \mathrm{H}^{\circ}$ or $\Delta \mathrm{G}^{\Theta}$. We can conclude that the driving factor governing the weakening of the other sites of an ion is not the energy of the first bond but the electron transfer it provokes. Thus, ions with several active sites appear as possessing some overall electron donor or electron acceptor ability. The activity of the second site is reduced the more this ability is utilized in the first bond. The $\Delta v$ shift brought about by a first ion-ligand $\mathrm{H}$-bond can be much larger than that of a cation-anion H-bond, although the energy of the latter is much larger, owing to the pure electrostatic interaction between the charges. The effect of the first hydrogen bond upon the possibility of formation of a second one depends thus more on covalent than on electrostatic effects.

\section{INFLUENCE OF ELECTRIC CHARGE OF IONS ON THERMODYNAMIC AND SPECTROSCOPIC CHARACTERISTICS OF HYDROGEN BONDS}

Does the presence of a netto charge in an ion directly influence its possibilities to form specific bonds? First of all we will observe that there is already some predestination for the cations to act as electron acceptors and for the anions to act as electron donors. But the presence of the charge is by no means a sufficient condition. Tetraalkylammonium cations or tetraphenylborate anions for instance are practically inactive in hydrogen bonding. Furthermore, when ions form hydrogen bonds, besides the increasing of the cohesion energy due to the transfer of electronic charge to the proton donor, pure electrostatic interactions have to be taken into account : charge-charge attraction for cation-anion $\mathrm{H}$-bonds and charge-dipole interactions for ion-ligand $\mathrm{H}$-bonds. These interactions have a direct influence on the stability and the other thermodynamic characteristics of these bonds. The covalent effects are determined by other factors. Thus, although cation-anion $\mathrm{H}$-bonds are as a rule much stronger than ion-ligand bonds, the frequency shifts $\Delta v$ may lie in the reverse order and can be, for the first bonds even smaller than those observed in H-bonds between neutral molecules. For inştance, the $\mathrm{H}$-bond between $\mathrm{Et}_{2} \mathrm{NH}_{2}^{+}$and $\mathrm{ClO}_{4}^{-}$, characterized by a stability constant of 460 $\mathrm{dm}^{3} \mathrm{~mol}{ }^{-1}$ in nitrobenzene at $25^{2} \mathrm{C}$ gives a frequency shift $\Delta \nu_{\mathrm{N}}^{+} \mathrm{H}$ of only $200 \mathrm{~cm}^{-1}$ (ref. 31 ).

Nevertheless we found a particular type of ion-ligand hydrogen bonds where the electric charge of the ion seems to play an essential role in the electron transfer and in the spectral characteristics of the specific bond (ref. 23).

The formation of this type of $\mathrm{H}$-bond requires two conditions : 1) the presence of a netto negative charge on the proton acceptor, and 2) the presence of an aromatic group susceptible to electronic delocalization in the vicinity of the AH bond of the proton donor. This is the case for the interaction between $\mathrm{I}^{-}$and diphenylguanidine :

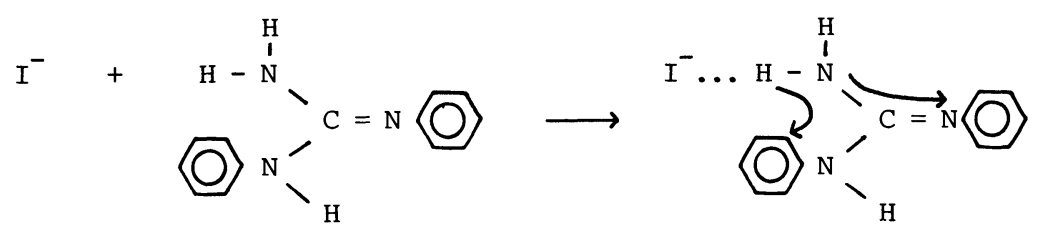

In the electric field exerted by the charge of the anion, the binding electrons of the $\mathrm{N}-\mathrm{H}$ group involved in the interaction with $\mathrm{I}^{-}$are pushed back towards the aromatic rings. As a consequence, this $\mathrm{N}-\mathrm{H}$ group becomes much more acidic and can form an hydrogen bond with the ion. Such phenomenon is not observed when the aromatic groups are replaced by alkyl ones. It is thus directly related to the possibility of electronic delocalization. We called therefore this particular type of cohesion forces : hydrogen bonding by charge induced electronic delocalization (CID).

We have found several independent experimental evidences for the existence of such CID hydrogen bonds :

1. The decrease of the Walden product $\mathrm{W}^{\circ}$ of $\mathrm{Hept}_{4}^{+} \mathrm{N}^{+} \mathrm{I}^{-}$in nitrobenzene upon addition of diphenylguanidine. At room temperature, at concentrations of the order of $10^{-4} \mathrm{M}$ this ionophore is practically completely dissociated in nitrobenzene. The limiting Walden product obtained from conductance and viscosity measurements decreases with increasing concentrations $L$ of diphenylguanidine. These experimental data cannot be explained by the solvation of the inert Hept $\mathrm{N}^{+}$cation and are ascribed to an interaction between $\mathrm{I}^{-}$and diphenylguanidine. This interaction reduces the individual walden product of the anion from $w_{0}$ to $w_{1}$. A quantitative treatment (ref. 23) leads to the expression

$$
\frac{1}{w_{O}^{\circ}-w_{L}^{\circ}}=\frac{1}{w_{0}^{-}-w_{1}^{-}}+\left(\frac{1}{w_{0}^{-}-w_{1}^{-}}\right) \frac{1}{k_{1}^{-}} \times \frac{1}{L}
$$


The experimental data follow indeed the relation

$$
\begin{aligned}
& 1 /\left(\mathrm{W}_{\mathrm{O}}^{\circ}-\mathrm{W}_{\mathrm{L}}^{\circ}\right)=6.33 \mathrm{ohm} \mathrm{\textrm {cm } ^ { - 2 } \mathrm { p } ^ { - 1 } \mathrm { mol }}+\frac{0.0904 \mathrm{ohm} \mathrm{cm}}{\mathrm{L}} \mathrm{p}^{-1} \mathrm{dm}^{-3} \mathrm{~mol} \\
&
\end{aligned}
$$

This vields ${ }_{1}$ the acceptable value of $0.158 \mathrm{ohm}^{-1} \mathrm{~cm}^{2} \mathrm{p} \mathrm{mol}^{-1}$ for the difference $\mathrm{w}_{0}^{-}-\mathrm{w}_{1}^{-}$and $70 \mathrm{dm}^{\mathrm{mol}}{ }^{-1}$ for the addition constant of diphenylguanidine on $\mathrm{I}^{-}$.

2. Complexation of both cations and anions of diphenylguanidinium iodide by diphenylguanidine in nitrobenzene. In contrast to Hept $\mathrm{N}^{+} \mathrm{I}$, $\mathrm{Ph}_{2} \mathrm{GuH}^{+} \mathrm{I}$ is only partly dissociated in nitrobenzene and the addition of $\mathrm{Ph}_{2} \mathrm{Gu}$ to the solution enhances the conductivity. However plots of $R$ versus $L$ show an upward curvature and the points follow eq. 15. This demonstrates that diphenylguanidine solvates not only the cation but also the iogide ion. The fiţting_of the experimental points yields two addition constants namely $27 \mathrm{dm}^{3} \mathrm{~mol}$ and $69 \mathrm{dm}^{-1} \mathrm{~mol}^{-1}$. The last value is in agreement with the addition constant $\mathrm{k}_{1}$ found above from independent experiments based on the Walden products. It is noteworthy that no upward curvature of $\mathrm{R}$ is observed for tetramethylguanidine added to solutions of tetramethylguanidinium iodide. The presence of an aromatic ring in the ligand seems thus indispensable in order to obtain high values of $\mathrm{k}_{1}$.

3. IR spectroscopic evidence for the formation of NH.... I $^{-}$hydrogen bonds by phenylsubstituted guanidiness. Diphenylguanidine in $\mathrm{CCl}_{4}$ solution exhibits two absorption bands at 3505 and $3408 \mathrm{~cm}$ ascribed to the antisymmetric and symmetric vibrations of the $\mathrm{NH}_{2}$ group. They decrease in intensity when Hept $\mathrm{N}^{+} \mathrm{I}^{-}$is added to the solution. Simultaneousiy two new bands appear at 3478 and $3300 \mathrm{~cm}^{-1}$. The last one corresponds obviously to the $\mathrm{N}-\mathrm{H}$ vibration in a

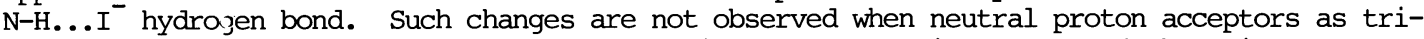
ethylamine or pyridine are added to the solution. The negative charge of the anion seems thus to play an essential role in the formation of such hydrogen bonds. The proximity of the counter charge in ion pairs must obviously reduce the effect, in comparison with free anions. The CID effect can explain the differences between the stabilities of the various $\mathrm{H}$-bonds formed by $4-\mathrm{NO}_{2}$ phenol and benzoic acid. The presence of an additional $\mathrm{C}-\mathrm{C}$ bond in the latter ligand reduces considerably the possibilities of electronic delocalization of the O-H group towards the aromatic ring. The experimental data are given in Table 2.

TABLE 2. Stability constants (in $\mathrm{dm}^{3} \mathrm{~mol}^{-1}$ ) of various hydrogen bonds in nitrobenzene at $25^{\circ} \mathrm{C}$ (ref. 23).

\begin{tabular}{|c|c|c|c|c|c|}
\hline Ligand & Ionophore & $\mathrm{k}_{1}^{-}$ & $\mathrm{k}_{2}^{-}$ & $\mathrm{K}$ & Curvature of $\mathrm{R} / \mathrm{L}$ \\
\hline $4-\mathrm{NO}_{2}$ phenol & $\mathrm{Et}_{3} \mathrm{NH}^{+} \mathrm{Br}^{-}$ & 2200 & 14 & 4 & upwards \\
\hline Benzoic acid & $\mathrm{Et}_{3} \mathrm{NH}^{+} \mathrm{Br}^{-}$ & 155 & 4 & 12 & downwards \\
\hline
\end{tabular}

Although $4-\mathrm{NO}_{2}$ phenol is a much weaker acid in water the addition constant $\mathrm{k}_{1}^{-}$on the free anion is much larger because of the CID effect. In the ion pair, the presence of the counter ion reduces this effect and $\mathrm{K}$ is smaller.

\section{HETEROCONJUGATION IN GAS PHASE AND DIFFERENCE IN PROTON AFFINITY}

The heteroconjugation of a cation $\mathrm{BH}^{+}$by a proton acceptor $\mathrm{A}$ can be considered as an intermediary step in the transfer of a proton from B to A

$$
\mathrm{BH}^{+}+\mathrm{A} \rightarrow[\mathrm{B} . . \mathrm{H} . . . \mathrm{A}]^{+} \rightarrow \mathrm{B}+\mathrm{HA}^{+}
$$

In the gaseous phase the difference in molar energy between the extreme states is equal to the difference $P A-P A=-\triangle P A$ between the proton affinities of the entities $A$ and $B$. In a similar way the heteroconjugation of an anion_ $A^{-}$by a proton donor $H B$ is an intermediate step in the transfer of a proton from the anion $\mathrm{B}^{-}$to the anion $\mathrm{A}^{-}$

$$
\mathrm{A}^{-}+\mathrm{HB} \rightarrow[\mathrm{A} . . \mathrm{H} . . \mathrm{B}]^{-} \rightarrow \mathrm{AH}+\mathrm{B}^{-}
$$

It is interesting to compare the enthalpy of formation of the H-bond with the difference in the proton affinities of the neutral moleculęs or of the anions. Such comparison was made by Kebarle and his coworkers (ref. 32) for $\mathrm{NH}^{+} \ldots \mathrm{O}$ and $\mathrm{O}-\mathrm{H}^{+} \ldots . \mathrm{O}$ cation-anion hydrogen bonds and extended by Mautner (ref. 33) to several ionic hydrogen bonds. The correlations between $-\Delta \mathrm{H}_{1 \mathrm{~A}}$, the enthalpy of formation of the H-bonds in the gas phase, and $\triangle \mathrm{PA}$ are linear only in a limited range, but in a broad $\triangle \mathrm{PA}$ range deviations from linearity were noticed. 


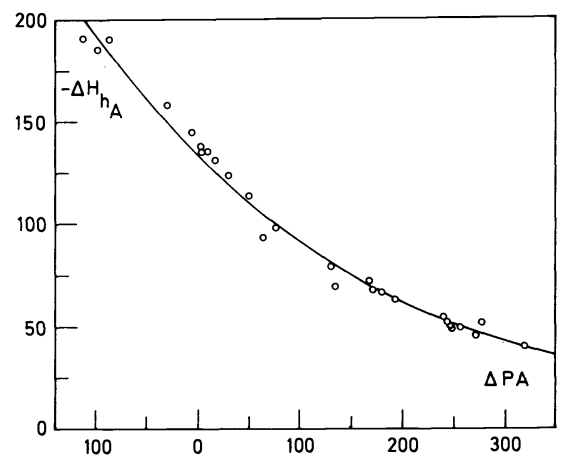

Fig. 10. Correlation of Th. Zeegers-Huyskens between the molar enthalpy of formation $\Delta \mathrm{H}_{\mathrm{hA}}$ of $\mathrm{O}-\mathrm{H} . . . \mathrm{X}^{-}\left(\mathrm{X}^{-}=\mathrm{F}, \mathrm{Cl}^{-}, \mathrm{Br}^{-}, \mathrm{I}^{-}\right)$ bonds in the gas phase and the difference in proton affinity of the oxygen anion and $\mathrm{X}^{-}$(units : $\mathrm{kJ} \mathrm{mol}^{-1}$ ) (ref. 34 ).

Investigating the correlation for some forty $0-\mathrm{H} . . . \mathrm{X}^{-}$hydrogen bonds ( $\mathrm{X}^{-}$being an halogenide ion) for negative as well as positive $\triangle \mathrm{PA}$ values, Th. Zeegers-Huyskens (ref. 34 ) proposed the following correlation :

$$
\begin{aligned}
& -\Delta \mathrm{H}_{\mathrm{hA}}=0+133.9 \mathrm{~kJ} \mathrm{~mol}^{-1} \exp \left(-0.00373|\Delta \mathrm{PA}| / \mathrm{kJ} \mathrm{mol}^{-1}\right) \text { when } \Delta \mathrm{PA}>0 \\
& -\Delta \mathrm{H}_{\mathrm{hA}}=\Delta \mathrm{PA}+133.9 \mathrm{~kJ} \mathrm{~mol}^{-1} \exp \left(-0.00373|\Delta \mathrm{PA}| / \mathrm{kJ} \mathrm{mol}^{-1}\right) \text { when } \Delta \mathrm{PA}<0
\end{aligned}
$$

$|\triangle \mathrm{PA}|$ is the absolute value of the difference in the proton affinities of $\mathrm{A}^{-}$and $\mathrm{B}^{-}$.

Of course, as pointed out by Th. Zeegers-Huyskens, all ion-molecule hydrogen bonds in the gas phase do not obey this correlation. In particular, steric hindrances may affect markedly the value of $\Delta \mathrm{H}_{h A}$. These steric hindrances are rather limited in the case of halogenide ions, but become very important in $\mathrm{O}-\mathrm{H} . . . \mathrm{O}^{-}$hydrogen bonds when both partners contain bulky groups. On the other hand the correlation breaks down for other functional groups such as S-H donors. Furthermore the correlation does not hold for the $\mathrm{F}-\mathrm{H}_{-} \mathrm{F}^{-}$complex, the H-bond enthalpy of which lies $27.2 \mathrm{~kJ}$ too high, or for the $\mathrm{Cl}^{-}-\mathrm{H}-\mathrm{Cl}$ complex for which the experimental value is $37.2 \mathrm{~kJ}$ too low.

But the correlation of Zeegers-Huyskens is remarkable from several points of view. First, it shows that the derivative of the function (see Fig. 10) is continuous in $\triangle \mathrm{PA}=0$, notwithstanding the unymmetric character of the $0-\mathrm{H} . . . \mathrm{x}^{-}$bond. On the other hand, if we consider the molar enthalpy lowering $-\Delta \mathrm{H}_{\mathrm{AB}}$ accompanying the formation of the complex_from the state of lowest energy of the separate partners (it is $A^{-}+H B$ for $\triangle \mathrm{PA}>0$ and $\mathrm{B}^{-}+\mathrm{HA}$ for $\triangle \mathrm{PA}<\mathrm{O}$ ) the equation of Zeegers-Huyskens leads to the general expression

$$
-\Delta \mathrm{H}_{\mathrm{AB}}=133.9 \mathrm{kJmol}^{-1} \exp \left(-0.00373|\Delta \mathrm{PA}| / \mathrm{kJ} \mathrm{mol}^{-1}\right)
$$

which has a maximal value at $|\triangle \mathrm{PA}|=0$. In $\mathrm{O}-\mathrm{H} . . . \mathrm{x}^{-}$hydrogen bonds the binding between the oxygen nucleus and the $X$ nucleus is the strongest when the proton affinity of the anions is the same. In this case the bridging proton is, on average, equally bonded to its two partners. Between these two bonds it is no longer possible to distinguish the chemical bond and the cohesion bond.

At the beginning of this article we define an H-bond (or a n- $\sigma$ EDAbond) as a cohesion force that competes with a given chemical bond. The correlation of zeegers-Huyskens shows that the cohesion between the partners is the strongest when this competition reaches its apogee.

\section{Acknowledgement}

The author wishes to thank Dr. Th. Zeegers-Huyskens and Dr. M.Cl. Haulait-Pirson for their fruitful discussions. He acknowledges the assistance of Mrs. R. Jungbluth-Hendrickx for the preparation of the manuscript and $\mathrm{Mr}$. R. Vandezande for the drawing of the figures.

\section{REFERENCES}

1. P. Huyskens, J. Mol. Struct. 135, 67-68 (1986).

2. J. D'Hondt and Th. Zeegers-Huyskens, J. Mol. Struct. 10, 135-145 (1971) (frequencies in $\mathrm{C}_{6} \mathrm{H}_{6}$ ); B. Tilquin and L. Lamberts, Z. Phys. Chem. NF $\overline{84}, 84-91$ (1973) (enthalpies of complexation in 1,2-dichloroethane). 
3. P. Huyskens and G. Siegel, Croatica Chemica Acta 55, 55-73 (1986) (Festschrift of Professor D. Hadzi).

4. W.F.K. Wynne-Jones, J. Chem. Soc., 795 (1931).

5. R.M. Fuoss, J. Amer. Chem. Soc. 80, 5059 (1958).

6. J.T. Denison and J.B. Ramsey, J. Amer. Chem. Soc. 77, 2615 (1955).

7. J. Barthel, Pure Appl. Chem. 51, 2093-2124 (1979).

8. E. Hirsch and R.M. Fuoss, J. Amer. Chem. Soc. 82, 1018 (1960).

9. J. Macau, L. Lamberts and P. Huyskens, Bull. Soc. Chim. France, 2387 (1971).

10. C.R. Witschonke and C.A. Kraus, J. Amer. Chem. Soc. 69, 2472 (1947).

11. V. Van Even and M.C. Haulait-Pirson, J. Solution Chem. 6, 757 (1977).

12. K. Bjerrum, K. Danske Vidensk. Selsk. 7, $\mathrm{N}^{\circ} 9$ (1926).

13. I.M. Kolthof and M.K. Chantooni, J. Amer. Chem. Soc. 85, 2195 (1963).

14. P. Huyskens and L. Neven, Bull. Soc. Chim. Belg. $88,7 \overline{61}$ (1979). N.G. Felix and P. Huyskens, J. Phys. Chem. 79, $23 \overline{16}$ (1975).

15. S. Winstein, E. Clippinger, A.H. Fainberg and G.C. Robinson, J. Amer. Chem. Soc. 76, 2597 (1954).

16. M. Szwarc Ed., Ions and ion-pairs in organic reactions, Wiley Interscience, New York (1972).

17. E.K. Ralph III and W.R. Gilkerson, J. Amer. Chem. Soc. 86, 4783 (1964). W.R. Gilkerson and J.B. Ezell, J. Amer. Chem. Soc. 89, 808 (1967).

18. L. Onsager, Phys. Z. 28, $277(1927)$. At higher ionic concentrations other terms have to be taken into account : R.M. Fuoss and L. Onsager, J. Phys. Chem. 61, 668 (1957); R.L. Kay, J. Amer. Chem. Soc. 82, 2099 (1960); J. Barthel, J., J.-C. Justice and R. Wachter, z. Phys. Chem. NF 84, 100 (1973); J. Barthel, Ionen in nichtwässrigen Lösungen, Steinkopff Darmstadt (1976).

19. R.M. Fuoss and F. Accascina, Electrolytic Conductance, Interscience New York (1959).

20. D. Pirson and P. Huyskens, J. Solution Chem. 3, 515 (1974). P. Huyskens and Y. Lambeau, J. Phys. Chem. 82, 1892 (1978).

21. J.F. Coetzee and G.R. Padmanbhan, J. Amer. Chem. Soc. 87, 5005 (1965).

22. M.C. Haulait-Pirson and P. Huyskens, J. Phys. Chem. 79,1812 (1975).

23. P. Huyskens, M.C. Haulait-Pirson, H. Collaer and D. Pirson, submitted for publication.

24. L. Sobczyk, H. Engelhardt and K. Bunze, The Hydrogen Bond, eds. Schuster, Zundel and Sandorfy, North Holland, Amsterdam (1976).

25. M. Born, Z. Physik 1, 45 (1920).

26. H.S. Frank and W.Y. Wen, Discuss. Faraday Soc. 24, 133 (1957).

27. V. Gutmann, Struct. Bonding 15, 141-66 (1973). See also F. Kohler and P. Huyskens, Adv. Mol. Relax. Proc. 8, $125-154$ (1976).

28. G. Poskin and P. Huyskens, Bull. Soc. Chim. France, 337 (1976).

29. J.B. Rulinda and Th. Zeegers-Huyskens, Proceedings 12th European Congress on Molecular Spectroscopy, Strasbourg, Elsevier Amsterdam $617(1976)$. For $\mathrm{Br}\left(\mathrm{N}^{+} \mathrm{Bu}_{4}\right)$ the ratio's $\mathrm{K}_{2} / \mathrm{K}_{1}$ are the average of those found at $30^{\circ} \mathrm{C}$ and $55^{\circ} \mathrm{C}$.

30. M.C. Haulait-Pirson and P. Huyskens, J. Phys. Chem. 79, 1812 (1975).

31. P. Huyskens, J. Amer. Chem. Soc. 99, 2578 (1977).

32. W.R. Davidson, J. Sunner and P. Kebarle, J. Amer. Chem. Soc. 101, 1679 (1979).

33. M. Mautner, J. Amer. Chem. Soc. 106, 1257 (1984) and C.V. Speller and M. Mautner, J. Phys. Chem. 89, 5217 (1985).

34. Th. Zeegers-Huyskens, Chem. Phys. Lett. 129, 172 (1986). 